Pacific Journal of Mathematic

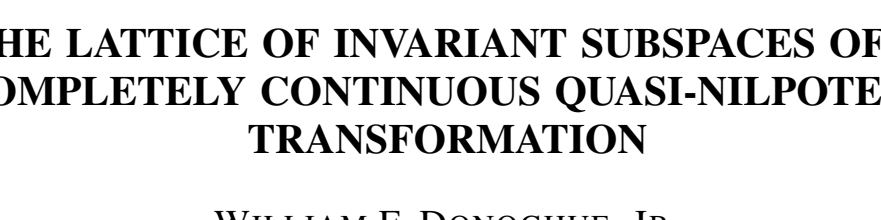




\title{
THE LATTICE OF INVARIANT SUBSPACES OF A COMPLETELY CONTINUOUS QUASI- NILPOTENT TRANSFORMATION
}

\author{
W. F. DONOGHUE, JR.
}

An essential result in the study of a continuous linear transformation of a Banach space into itself is the specification of the lattice of proper closed subspaces of the Banach space which are invariant under the transformation. For certain classes of transformations the results which have been obtained in this direction may be regarded as complete, for example, for self-adjoint transformations in Hilbert space. The invariant subspaces for certain isometries in Hilbert space have been found by Beurling [2] whose results have been extended to unitary transformations by the author [3]. In general, however, little is known; in fact, it is not yet known that an arbitrary continuous linear transformation in Hilbert space has nontrivial closed invariant subspaces. A theorem of von Neumann guarantees that a completely continuous transformation in Hilbert space has such subspaces, while more recent work of Aronszajn and Smith [1] establishes the same result for any Banach space. For completely continuous transformations which contain only the point 0 in the spectrum (the quasi-nilpotent transformations), spectral theory can provide no information concerning the invariant subspaces, and the application of the result of Aronszajn and Smith only assures the existence of a nested sequence of closed invariant subspaces. Such a lattice of invariant subspaces is considerably simpler in structure than that usually encountered in spectral theory. It is the purpose of this note to show that more cannot be obtained, and that this very simple lattice does in fact occur. The three examples which follow illustrate this fact; the fourth example shows that not every completely continuous quasi-nilpotent transformation has such a lattice of invariant subspaces.

ExAMPLE 1. Let $\mathscr{H}$ be the Hilbert space consisting of all functions

$$
f(z)=\sum_{n=0}^{\infty} a_{n} z^{n}
$$

analytic in $|z|<1$ with Taylor coefficients in $l^{2}$ :

$$
\sum_{n=0}^{\infty}\left|a_{n}\right|^{2}=\|f\|^{2}<\infty .
$$

Received June 25, 1956. Paper written under contract with Office of Naval Research, Contract Nonr 58304. 
We may also write

$$
(f, g)=\sum_{n=0}^{\infty} a_{n} \bar{b}_{n}=\frac{1}{2 \pi} \int_{0}^{2 \pi} f\left(e^{i \theta}\right) \overline{g\left(e^{i \theta}\right)} d \theta
$$

where

$$
g(z)=\sum_{n=0}^{\infty} b_{n} z^{n}
$$

Let $V$ be the transformation defined by $V f(z)=z f(z / 2) ; \quad V$ is completely continuous and quasi-nilpotent. Let $\mathscr{C}_{n}$ be the subspace of $\mathscr{H}$ composed of functions $f(z)$ which have a zero of order $\geqq n$ at the origin; it is evident that these subspaces satisfy the relation $\mathscr{M}_{n+1} \subset \mathscr{M}_{n}$ and that they are closed and invariant under $V$. It will be shown that these are the only nontrivial closed invariant subspaces.

For the proof, it is enough to consider an element $f$ of $\mathscr{C}$ for which $f(0) \neq 0$ and to show that the sequence $V^{n} f(n \geqq 0)$ spans $\mathscr{K}$. We may suppose $f(0)=1$ and write $f(z)=1+g(z)$ with $g$ in $\mathscr{L}_{1}$. For $n \geqq 0$ we define $h_{n}(z)=\sqrt{ } 2^{\left(n^{2}-n\right)} V^{n} f$; it is sufficient to show that the sequence $h_{n}$ spans the space. For this purpose, consider the linear transformation $T$ defined by $T\left(z^{n}\right)=h_{n}(z)$; it is easy to establish the continuity of $T$, and it will now be shown that $T$ has a continuous inverse, thereby establishing the completeness of $h_{n}$. Note first that

$$
\left\|(T-I) z^{n}\right\|^{2}=\left\|h_{n}(z)-z^{n}\right\|^{2}=\left\|f\left(z / 2^{n}\right)-1\right\|^{2}=\left\|g\left(z / 2^{n}\right)\right\|^{2} \leqq \begin{gathered}
\|g\|^{2} \\
4^{n}
\end{gathered} .
$$

On the other hand, if $f_{2}(z)$ is a sequence in $\mathscr{C}$ weakly converging to 0 then

$$
f_{\nu}(z)=\sum_{n=0}^{\infty} \alpha_{n}^{(\nu)} z^{n}
$$

and

$$
\left\|(T-I) f_{2}\right\| \leqq \sum_{n=0}^{\infty}\left|a_{n}^{(\nu)}\right|\left\|h_{n}-z^{n}\right\| \leqq\|g\| \sum_{n=0}^{\infty}\left|a_{n}^{(\nu)}\right|\left(1 / 2^{n}\right)
$$

(the inequality above following in general from its truth for finite sums). From the weak convergence of the $f_{\nu}$ to 0 it is clear that

$$
\lim _{\nu} \sum_{n=0}^{\infty}\left|a_{n}^{(\nu)}\right|\left(1 / 2^{n}\right)=0
$$

hence that $(T-I) f_{\nu \nu}$ converges strongly to 0 and therefore that $T-I$ is completely continuous. Accordingly 0 is in the resolvent set of $T$ or there exists a finite-dimensional null space for $T$. Thus $T^{-1}$ exists and 
is continuous, since the nonexistence of a null space for $T$ is shown as follows: $T f=0$ for

$$
f(z)=\sum_{n=0}^{\infty} a_{n} z^{n}
$$

means

$$
\sum_{n=0}^{\infty} a_{n} h_{n}(z)=0
$$

whence

$$
a_{0} h_{0}(z)+\sum_{n=1}^{\infty} a_{n} h_{n}(z)=0
$$

the second term is in $\mathscr{h}_{1}$, hence the first term is, and since $h_{0}$ is not in that subspace it follows that $a_{0}=0$; from an inductive argument it then follows that all $a_{n}=0$, as desired.

EXAMPLE 2. Let $V^{*}$ be the adjoint of the transformation $V$ described above. The invariant subspaces for $V^{*}$ are the orthogonal complements of the invariant subspaces for $V$, and form an increasing sequence of finite-dimensional subspaces. Clearly $V^{*}$ is completely continuous and quasi-nilpotent.

EXAMPLE 3 . If $f(t)$ is a function integrable on the interval $0 \leqq t \leqq 1$ let $S f$ be the indefinite integral

$$
S f(t)=\int_{0}^{t} f(x) d x
$$

The operator $S$ is the Volterra integral operator and is completely continuous and quasi-nilpotent when considered as a transformation from $L^{p}$ into itself for $1 \leqq p<\infty$, or when considered on the space $\mathscr{C}$ of continuous functions on the interval. If $\mathscr{M}_{s}$ denotes the class of all functions in $L^{p}$ which vanish almost everywhere on the interval $0 \leqq t$ $\leqq s$ it is clear that the $\mathscr{L}_{s}$ form closed subspaces of $L^{p}$ which are invariant under $S$. It will be shown that such subspaces are the only closed invariant subspaces of the operator $S$.

For the proof, the result is first established for the continuous function space. Let $f(t)$ be continuous on the interval $0 \leqq t \leqq 1$ and define $f=0$ outside that interval to obtain a function defined throughout the axis. If $Y(t)$ is the Heaviside function equal to 1 on the positive half-axis and vanishing on the negative half-axis, then for all $x$ in the unit interval

$$
S f(x)=(Y * f)(x)
$$


where * denotes convolution. Similarly, the iterates of $S$ applied to $f$ are given for $0 \leqq x \leqq 1$ by

$$
S^{n} f(x)=\left(Y_{n} * f\right)(x)
$$

where $Y_{n+1}(t)$ vanishes on the left half-axis and equals $t^{n} / n$ ! on the right. Let $\mu$ be a measure on the unit interval orthogonal to all $S^{n} f$; the equation

$$
\int_{0}^{1} S^{n} f(x) d \mu=0
$$

may be written $\left(Y_{n} * f * \check{\mu}\right)(0)=0$ where $\check{\mu}$, the reflection of $\mu$ through the origin, is given by $\breve{\mu}(t)=\mu(-t)$. From the associativity of convolution, then, $\left(Y_{n} *(f * \check{\mu})\right)(0)=0$ whence it follows that the continuous function $f * \check{\mu}$ is orthogonal to $\check{Y}_{n}(t)=Y_{n}(-t)$ for all $n \geq 0$. Accordingly $f * \breve{\mu}$ vanishes on the left half-axis. A theorem, the most general version of which is due to J. Lions [4] asserts that for any two distributions on $R^{n}$ with compact support, the convex hull of the support of the convolution is the vectorial sum of the convex hulls of the supports of the factors. Thus if the convex hull of the support of $\mu$ is the interval $(c, d)$ and the convex hull of the support of $f$ is $(a, b)$ it follows that the interval $(a-d, b-c)$ is the convex hull of the support of $f * \check{\mu}$, whence $d \leqq a$. Thus the only measures orthogonal to $S^{n} f, n \geqq 0$ are measures orthogonal to the subspace $\mathscr{C}_{a}$ and the closed linear span of that sequence is $\mathscr{M}_{a}$, unless $a=0$, in which case the closed linear span will be the whole space if $f(0) \neq 0$. Thus any proper invariant subspace for $S$ in $\mathscr{C}$ is a union of spaces of type $\mathscr{C l}_{s}$ and is therefore a space of that type itself.

For the spaces $L^{p}$ the same result follows from the observation that the range of $S$ is contained in $\mathscr{C}$. If the smallest interval containing the support of $S f$ is $(a, b)$, then the sequence $S^{n} f, n \geqq 1$ spans the subspace $\mathscr{C}_{a}$ of $\mathscr{C}$ and its closure in $L^{p}$ is the corresponding $\mathscr{L}_{a}$ of that space. Evidently $f(t)=0$ almost everywhere in $0 \leqq t \leqq a$, whence $S^{n} f$, $n \geqq 0$ spans $\mathscr{H}_{a}$ in $L^{p}$.

It is of interest to note that our assertion is no longer true for the space $L^{\infty}$. As above, the transformation $S$ is completely continuous and quasi-nilpotent, however, its range is contained in a separable subspace of the nonseparable $L^{\infty}$. It is possible to obtain any closed invariant subspace of $L^{\infty}$ by choosing any closed subspace of a subspace of the type $\mathscr{C}_{a}$ which contains the corresponding continuous function subspace $\mathscr{C}_{a}$. Nevertheless, if the word closed were interpreted to mean weak-star closed the result obtained above for $\mathscr{C}$ and $L^{p}$ would carry over to $L^{\infty}$. 
EXAMPLE 4 . Let $\mathscr{C}$ be the separable Hilbert space consisting of functions $f(x, y)$ defined in the unit square for which

$$
\|f\|^{2}=\int_{0}^{1} \int_{0}^{1}|f(t, s)|^{2} d s d t<\infty .
$$

On $\mathscr{H}$ consider the integral operator $T$ defined by

$$
T f(x, y)=\int_{0}^{x} \int_{0}^{y} f(t, s) d s d t .
$$

$T$ is completely continuous and quasi-nilpotent. Following the methods of the previous example it is not difficult to construct a class of subsets of the square corresponding to a class of invariant subspaces. Obviously the linear subspaces so obtained are not linearly ordered under inclusion; moreover these are not all of the invariant subspaces since the subspace consisting of functions which depend only on the product $x y$ is also a closed invariant subspace for $T$.

\section{REFERENCES}

1. N. Aronszajn and K. T. Smith, Invariant subspaces of completely continuous operators, Ann. of Math., 60 (1954), 345-350.

2. A. Beurling, On two problems concerning linear transformations in Hilbert space. Acta Math., (1949), 239-255.

3. W. F. Donoghue, Invariant subspaces of unitary transformations. Bull. Amer. Math. Soc., 59 (1953), 535.

4. J. L. Lions, Supports dans la transformation de Laplace. Journ. d'Analyse Math., 2 (1952), 369-379.

UNIVERSITY OF KANSAS 



\section{PACIFIC JOURNAL OF MATHEMATICS}

\section{EDITORS}

H. L. ROYDEN

Stanford University

Stanford, California

R. A. Beaumont

University of Washington

Seattle 5, Washington

\section{A. L. Whiteman}

University of Southern California

Los Angeles 7, California

E. G. Straus

University of California

Los Angeles 24, California

\section{ASSOCIATE EDITORS}
E. F. BECKENBACH
C. E. BURGESS
M. HALL
E. HEWITT

\author{
A. HORN \\ V. GANAPATHY IYER \\ R. D. JAMES \\ M. S. KNEBELMAN
}

L. NACHBIN

I. NIVEN

G. SZEKERES

T. G. OSTROM

M. M. SCHIFFER
F. WOLF

K. YOSIDA

\section{SUPPORTING INSTITUTIONS}

\author{
UNIVERSITY OF BRITISH COLUMBIA \\ CALIFORNIA INSTITUTE OF TECHNOLOGY \\ UNIVERSITY OF CALIFORNIA \\ MONTANA STATE UNIVERSITY \\ UNIVERSITY OF NEVADA \\ OREGON STATE COLLEGE \\ UNIVERSITY OF OREGON \\ UNIVERSITY OF SOUTHERN CALIFORNIA
}

\author{
STANFORD UNIVERSITY \\ UNIVERSITY OF UTAH \\ WASHINGTON STATE COLLEGE \\ UNIVERSITY OF WASHINGTON \\ AMERICAN MATHEMATICAL SOCIETY \\ CALIFORNIA RESEARCH CORPORATION \\ HUGHES AIRCRAFT COMPANY \\ THE RAMO-WOOLDRIDGE CORPORATION
}

Mathematical papers intended for publication in the Pacific Journal of Mathematics should be typewritten (double spaced), and the author should keep a complete copy. Manuscripts may be sent to any of the editors. All other communications to the editors should be addressed to the managing editor, E. G. Straus at the University of California, Los Angeles 24, California.

50 reprints per author of each article are furnished free of charge; additional copies may be obtained at cost in multiples of 50 .

The Pacific Journal, of Mathematics is published quarterly, in March, June, September, and December. The price per volume (4 numbers) is $\$ 12.00$; single issues, $\$ 3.50$. Back numbers are available. Special price to individual faculty members of supporting institutions and to individual members of the American Mathematical Society: $\$ 4.00$ per volume; single issues, $\$ 1.25$.

Subscriptions, orders for back numbers, and changes of address should be sent to Pacific Journal of Mathematics, 2120 Oxford Street, Berkeley 4, California.

Printed at Kokusai Bunken Insatsusha (International Academic Printing Co., Ltd.), No. 10, 1-chome, Fujimi-cho, Chiyoda-ku, Tokyo, Japan.

PUBLISHED BY PACIFIC JOURNAL OF MATHEMATICS, A NON-PROFIT CORPORATION

The Supporting Institutions listed above contribute to the cost of publication of this Journal, but they are not owners or publishers and have no responsibility for its content or policies. 


\section{Pacific Journal of Mathematics}

\section{Vol. 7, No. 2 \\ February, 1957}

William F. Donoghue, Jr., The lattice of invariant subspaces of a completely continuous quasi-nilpotent transformation ................... 1031

Michael (Mihály) Fekete and J. L. Walsh, Asymptotic behavior of restricted extremal polynomials and of their zeros.................... 1037

Shaul Foguel, Biorthogonal systems in Banach spaces ............... 1065

David Gale, A theorem on flows in networks ................... 1073

Ioan M. James, On spaces with a multiplication .................. 1083

Richard Vincent Kadison and Isadore Manual Singer, Three test problems in operator theory .................................... 1101

Maurice Kennedy, A convergence theorem for a certain class of Markoff processes........................................ 1107

G. Kurepa, On a new reciprocity, distribution and duality law ........ 1125

Richard Kenneth Lashof, Lie algebras of locally compact groups ........ 1145

Calvin T. Long, Note on normal numbers .................... 1163

M. Mikolás, On certain sums generating the Dedekind sums and their reciprocity laws ..................................... 1167

Barrett O'Neill, Induced homology homomorphisms for set-valued maps......................................... 1179

Mary Ellen Rudin, A topological characterization of sets of real numbers........................................... 1185

M. Schiffer, The Fredholm eigen values of plane domains 1187

F. A. Valentine, A three point convexity property .........

Alexander Doniphan Wallace, The center of a compact lattice is totally

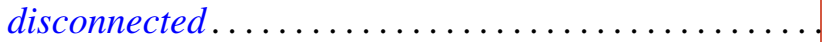

Alexander Doniphan Wallace, Two theorems on topological lattices.

G. T. Whyburn, Dimension and non-density preservation of mappings...

John Hunter Williamson, On the functional representation of certain algebraic systems ... 